\title{
Patterns of Change in Prayer Activity, Expectancies, and Contents During Older Adulthood
}

\author{
R. DAVID HAYWARD \\ School of Public Health \\ University of Michigan
}

\author{
NeAL KRAUSE \\ School of Public Health \\ University of Michigan
}

\begin{abstract}
Prayer is the most common form of religious practice and a central part of religious experience, yet little is known about whether individuals' prayer activities and beliefs tend to remain stable or develop over the life course. This study examines change during the course of older adulthood in a range of dimensions of prayer, including total frequency of private prayer, specific beliefs and expectancies regarding prayer, and the contents of prayers. Data come from four waves of an ongoing longitudinal survey of Christian older adults, covering a period of seven years. Growth curve analysis was used to model patterns of within-person change in these factors. Linear increase was observed in total prayer frequency and in beliefs about prayer emphasizing placing trust in God over expecting immediate rewards. Frequency of prayer increased for all types of prayer contents, including prayers for others, for God's will, in thanksgiving, for guidance, for health, and for material goods. Only the belief that one's prayers are answered remained stable during the course of the study. Results highlight the dynamic nature of prayer beliefs and behaviors in late life, and partially support a pattern of growing faith maturity.
\end{abstract}

Keywords: prayer, aging, older adults, expectancies, growth curve analysis.

\section{INTRODUCTION}

Prayer has long been a subject of interest to researchers, as a central element of religious practice (Heiler 1932; James 1902). Indeed, prayer represents the most common form of religious behavior among Americans, 58 percent of whom report praying at least once each day (Pew Forum 2008). Moreover, prayer has been found to be related to a range of health and well-being outcomes (Masters and Spielmans 2007; Whittington and Scher 2009). But although it is understood that prayer is a complex phenomenon that may take on a variety of forms stemming from a range of motivations and beliefs about its efficacy (Krause 2004; Ladd and Spilka 2002), little is known about how individuals' prayer beliefs and behavior may change over time.

Although changes during the course of older adulthood have received relatively little attention from researchers, this may be an especially important stage of life in which to examine prayer. The oldest old (i.e., those aged 85 and older) are the fastest growing demographic group worldwide (United Nations 2010) and in the United States alone the number of centenarians is expected to grow nearly 10-fold by 2050 (U.S. Census Bureau 2008). As a result, a sizeable number of people who have reached age 65 can expect to live for another 35 years or more, and it is reasonable to assume that change and development continue throughout this span. Older adulthood is marked by myriad changes in social relationships and physical needs, and is also a time during which religious engagement often intensifies (Krause 2008). As such, older adults 
may be highly motivated to adapt both the ways that they pray and their beliefs about prayer in general, in response to their changing circumstances and the increasing salience of religion. Although several recent studies have examined prayer among older adults, we know of none that address the possibility of changes occurring during the course of late life. This study addresses that gap in the literature by examining patterns of stability and change in individual prayer activity, beliefs, and contents, using a longitudinal survey of Christians conducted during older adulthood.

\section{Elements of Prayer}

Prayer is a complex phenomenon, taking on a variety of modes of expression (Ladd and Spilka 2002; Poloma and Pendleton 1989; Whittington and Scher 2009). Researchers have drawn distinctions between types of prayer, including colloquial, petitionary, ritual, and meditative. Each type entails particular forms of practice, and each may also have distinct influences on key outcomes, such as health and well-being (Poloma 1991). These practices, and moreover their meaning for practitioners, also vary considerably across cultures and religious traditions. Because of this heterogeneity, this study focuses specifically on the practices of members of Christian religious groups. Although there are undoubtedly many differences in prayer behavior among various Christian denominations, it is possible to make some generalizations across these groups on the basis of existing prayer research.

Related to differences among forms of prayer are more general differences in beliefs about prayer. Individuals' reasons for praying may vary considerably; for example, it may be perceived as an obligation to God, part of a personal dialogue with the divine, or as part of an exchange relationship in which personal benefit is sought. Central to these beliefs are expectancies about prayer: what outcome, if any, it is anticipated that a prayer will produce. Research in the area of prayer expectancies has demonstrated considerable variability in this element of belief, with some individuals anticipating quick and tangible responses to their requests, whereas others expect God to respond slowly and obliquely or not at all (Krause 2004).

Prayer expectancies may influence the amount and type of prayer behavior in which people engage in a number of ways. Although the expectation that prayers will be promptly rewarded may motivate more frequent prayer, it may also lead to religious disillusionment or even anger with God, if one's requests are not fulfilled (Exline, Yali, and Lobel 1999). Conversely, the belief that God responds to prayers more slowly and ambiguously but can be counted on to have one's ultimate best interests in mind, which Krause (2004) characterizes as trust-based expectancies, is less susceptible to disconfirmation as the result of negative experiences. Since an immediate response is not expected from each prayer, those holding this type of expectancy can reinterpret apparently unfulfilled requests as evidence of God's wisdom and ability to address problems by other means, rather than as evidence that God has failed (Krause et al. 2000).

Expectancies may also have an impact on the contents of individuals' prayers. Contents may be fairly incidental in some forms of prayer, such as those recited ritually or as part of meditation, but in a large number of cases prayers are focused on at least one particular subject (Baker 2008). Distinctions can be drawn based on whether the subject is the self, other specific individuals, or a diffuse category. In each case the specific contents may vary as well, ranging from material gain to health to purely spiritual benefits (Krause and Chatters 2005). For example, praying to receive material goods might be common among those holding a relatively self-focused faith, whereas praying for the salvation of others might be thought to reflect a more mature theological orientation (Fowler 1991; Streib 2001).

At the same time, praying for specific benefits for oneself or another known individual may be more likely to generate frustrated expectancies, since it posits a specific and easily monitored 
set of conditions for fulfillment, whereas more general prayer contents are likely to be more compatible with trust-based prayer expectancies. In addition to expectancies related to God, social expectancies and group engagement may play an important role in the degree to which one prays on the behalf of others. Recent research has shown that the belief that others are praying for you is associated with better mental health outcomes (Krause 2011). This perception may also help to enmesh an individual in a set of social exchange relationships, so that those who believe others pray for them may reciprocate by in turn praying for others.

Situational factors, like stressful life events and personal health, may also play a role in prayer. The relationship between prayer and health has been a subject of particular interest to researchers, although the directionality of this relationship and the mechanisms by which it may operate remain ambiguous. Prayer is a prevalent coping mechanism used by many when faced with health problems (McCaffrey et al. 2004), but prayer has also been associated in turn with better health outcomes (Masters and Spielmans 2007). Some studies suggest that prayer can contribute to psychoneuroimmunological pathways that promote positive health outcomes, but these results remain mixed (Ai, Seymour et al. 2009; Ai, Wink et al. 2009). Prayer may also help to strengthen social ties to the religious group (e.g., Sosis 2004), in turn allowing for better activation of social support networks in times of need (Krause 2002). Thus, the relationship between prayer and health appears to be complex and reciprocal but it also provides an impetus for examining the development of prayer activity, especially in late life as health problems tend to become more severe.

\section{The Role of Aging in Prayer}

In the context of the present study, a central question regards the role of aging in prayer. Although the issue has not been definitively resolved, many researchers contend that individuals tend to become more religious in general as they grow older (Krause 2008). Consistent with this view, cross-sectional survey data show that older adults engage in prayer more often than younger adults (Baker 2008; Levin and Taylor 1997). If religion takes on a more central role during late life, it follows that prayer should become a more salient and habitual response to coping with life's pressures. But even independent of increasing levels of general religiousness, other social changes occurring in older adulthood may also prompt increasing levels of prayer. First, declining health both for oneself and for spouses and friends in the same age cohort may encourage more prayer, since prayer is a common method of coping with health problems (McCaffrey et al. 2004). Second, prayer may serve as a means of staying engaged in reciprocal social relationships. As they age, individuals may find it increasingly difficult to repay help received from others by offering direct tangible assistance, and may thus instead pray more for others as a means of fulfilling their side of these mutual obligations. Finally, although religious participation appears to increase during older adulthood, physical disabilities may also begin to negatively affect attendance at public worship services among the oldest old (Kelley-Moore and Ferraro 2001). Private prayer may increase as a way of remaining religiously engaged in the face of these declines.

Very little is known about how age may affect prayer expectancies or contents. However, it is plausible that aging in older adulthood may bring about changes in spiritual maturity that help to shape these beliefs and behaviors over time. Some empirical evidence for this basic process comes from the opposite end of the age spectrum: within childhood. In a cross-sectional study comparing children at various stages of development, Bamford and Lagattuta (2010) found that four- and six-year-old children believed that prayer was used exclusively to express positive emotions, whereas eight-year-old children and adults believed that prayer was also used to cope with negative emotions. These changes are at least broadly consistent with movement through the earliest of Fowler's (1991) stages of faith development, proceeding from an intuitive to a 
literal understanding of religion. The developmental perspective on religious change (Fowler 1991; Streib 2001) construes certain age-related patterns of faith as related to cognitive and psychodynamic change, and draws heavily from developmental theories of personality, such as Erikson's (1968).

Although the faith development model offers less guidance when it comes to older adulthood, it may be useful to compare with the Eriksonian perspective, which posits a late life crisis of integrity versus despair, marked by introspection and self-evaluation. Most investigators do not appreciate the extent of the influence that religion exerts in Erikson's (1968) final stage of development. Evidence of this may be found in Hoare's review of his private papers (2002). She observes that as Erikson grew older, "he changed his thinking to build in God.... Faith then became an alternative term for integrity" (Hoare 2002:90). In addition to its implications for religious change more broadly, this type of late life shift may influence prayer beliefs and practices specifically. For example, it may prompt reflection and contemplation that lead to more trust-based prayer expectancies, and greater maturity in prayer contents. This framework suggests that the course of older adulthood is likely to be a time of particularly rapid change in factors related to prayer.

Any such changes in beliefs about prayer also have the potential to contribute to changes in the contents of prayer, as may changes in the social environment. Some of these changes may simply reflect practical changes in needs. For example, personal health is likely to become a more common subject as health begins to decline. Social ties may play an important role as well. As people get older, the size of their social networks tends to decline, as they begin to focus on a smaller number of closer relationship (Carstensen, Isaacowitz, and Charles 1999). Although this may imply a decreasing number of other individuals to pray for, it is also possible that the emotional intensification of these ties increases the motivation to pray on the behalf of these close significant others. Furthermore, since religious participation intensifies in late life, it is likely that members of one's religious congregation are likely to be disproportionately represented among this closest set of ties, making them more salient as subjects of prayer, and creating a stronger set of social expectations to engage in reciprocal prayer.

\section{HYPOTHESES}

Based on the theoretical foundations outlined earlier, as well as on previous cross-sectional research, this study proposes four hypotheses relating to changes during older adulthood in prayer frequency, prayer expectancies, and prayer contents.

H1: Older adults will engage in private prayer significantly more frequently as they age, consistent with increasing religious salience.

H2: Older adults' beliefs regarding prayer will shift significantly away from expecting immediate prayer response, and toward more trust-based expectancies, consistent with increasing maturity of faith.

H3: The contents of older adults' prayers will shift away from personal and material rewards, and toward a greater focus on others and general spiritual matters, consistent with increasing maturity of faith.

H4: Each of the patterns of the three general patterns of change predicted in H1-H3 will be intensified by engagement in a religious community, such that older adults with greater involvement increase their prayer behavior and maturity of prayer beliefs and contents at a faster rate than those who are less involved in the church. 


\section{Methods}

\section{Sample}

Data used in this study came from the first four waves of an ongoing longitudinal survey examining religion and health in older adults. In 2001, a random sample of U.S. residents aged 66 or older (excluding residents of Alaska and Hawaii) was drawn from the beneficiary list of the Centers for Medicare and Medicaid Services. Because of the specific focus of the survey, the sample was screened by race and religious background. To allow for oversampling of minority respondents, only older adults identifying as either white or black were included. Because a number of measures of religious factors were designed and validated for use only among Christians, the sample was screened so that respondents' religious affiliation was limited to the following categories: currently Christian, formerly Christian but currently practicing no religion, or had never been affiliated with any religion. Technical details regarding sampling procedures for this survey have been fully described by Krause (2002).

The initial survey (Wave 1) was conducted in 2001, with 1,500 respondents (752 African American, 748 white), and a response rate of 62 percent. Subsequent surveys waves were carried out in 2004 (Wave 2), 2007 (Wave 3) , and 2008 (Wave 4). There were a total of 1,024 respondents in Wave 2 (with an 80 percent reinterview rate, excluding respondents who had died or became ineligible due to institutionalization in the interim), 969 in Wave 3 (75 percent reinterview rate), and 718 in Wave 4 (88 percent reinterview rate). ${ }^{1}$ Harris Interactive (New York) conducted all surveys via in-person interview in respondents' homes.

\section{Measures}

Key prayer constructs include total frequency of private prayer, beliefs about prayer efficacy, and contents of private prayers. Three specific beliefs about prayer efficacy were examined: the perception that one's prayers are answered quickly, the belief that one must learn to wait for prayers to be answered, and the belief that God does not always grant prayer requests because he knows what is best. Six specific elements of private prayer contents were measured: prayer for others, for God's will to be done, for thanksgiving, for guidance, for health, and for material goods. Additional religious constructs used as predictors of prayer change included frequency of worship attendance, and spiritual support (a dimension of congregational support addressing social support relating directly to religious/spiritual beliefs and experiences). Spiritual support was measured using a five-item scale (Cronbach's $\alpha=.917$ ) and was asked only of respondents who said that they attended worship services more than a few times a year. ${ }^{2}$ Question wording and response categories for all of these items are specified in Table 1.

\footnotetext{
${ }^{1}$ Although the procedures used here include all observations, including those for who died or left the sample, individuals with more complete observations receive more weight in estimation of the results, and thus it is important to evaluate the impact of attrition. Auxiliary analyses (not reported) were run including a binary variable indicating attrition status (remained for four waves vs. dropped out) as a main effect and in interaction with age. Significant differences in slopes were detected for two prayer outcomes. "Learning to wait" increased over time in both groups, but significantly more rapidly in the nonattrition group. "Prayer for personal health" showed significant increase only in the nonattrition group. These patterns do not substantially affect interpretation of the main results.

${ }^{2}$ Note that the inclusion of this variable effectively limits the sample analyzed to those participants who reported church attendance more than a few times per year. This may introduce bias from two sources: participants with declining attendance, who drop out of the sample early, and those with constant low attendance. Auxiliary analyses excluding spiritual support and including an indicator of dropout status (not reported) show no impact on the results as a result of early attrition from this source. Auxiliary analyses comparing chronic low attenders with the rest of the sample (not
} 
Table 1: Survey items

Prayer frequency

A. How often do you pray by yourself? ${ }^{\mathrm{a}}$

Prayer beliefs

B. How often are your prayers answered? ${ }^{\mathrm{b}}$

C. Learning to wait for God's answer to my prayers is an important part of my faith. ${ }^{\mathrm{c}}$

D. When I pray, God does not always give me what I ask for because only He knows what is best. $^{\mathrm{c}}$

Prayer contents

E. When you are by yourself, how often do you pray for other people? ${ }^{\mathrm{a}}$

F. When you're by yourself, how often do you pray that God's will be done? ${ }^{\text {d }}$

G. When you're by yourself, how often do you offer prayers of thanksgiving? ${ }^{\text {d }}$

H. When you're by yourself, how often do you pray for guidance? ${ }^{\mathrm{d}}$

I. When you're by yourself, how often do you pray for your own health? ${ }^{\text {d }}$

J. When you're by yourself, how often do you pray for material things, like a job, money, or a car? $^{\mathrm{d}}$

Attendance

K. How often do you attend religious services? ${ }^{\mathrm{e}}$

Spiritual support

L.1. Not counting Bible study groups, prayer groups, or church services, how often does someone in your congregation share their own religious experiences with you ${ }^{\mathrm{d}}$

L.2. Not counting Bible study groups, prayer groups, or church services, how often does someone in your congregation help you find solutions to your problems in the Bible? ${ }^{d}$

L.3. Not counting Bible study groups, prayer groups, or church services, how often do the examples set by others in your congregation help you lead a better religious life? ${ }^{\mathrm{d}}$

L.4. Not counting Bible study groups, prayer groups, or church services, how often does someone in your congregation help you to know God better? ${ }^{\mathrm{d}}$

L.5. Not counting Bible study groups, prayer groups, or church services, how often does someone in your congregation help you live according to your religious beliefs? ${ }^{\mathrm{d}}$

${ }^{a}$ Responses (scores): never (1), less than once a month (2), once a month (3), a few times a month (4), once a week (5), a few times a week (6), once a day (7), several times a day (8).

${ }^{\mathrm{b}}$ Responses (scores): never (1), sometimes (2), often (3), always (4).

${ }^{\mathrm{c}}$ Responses (scores): strongly disagree (1), disagree (2), agree (3), strongly agree (4).

${ }^{\mathrm{d}}$ Responses (scores): never (1), once in a while (2), fairly often (3), very often (4).

${ }^{\text {e}}$ Responses (scores): never (1), less than once a year (2), about once or twice a year (3), several times a year (4), about once a month (5), two to three times a month (6), nearly every week (7), every week (8), several times a week (9).

Demographic variables included race, gender, years of education, and birth cohort. Birth cohort membership was defined by five-year intervals, which provides a good fit with the distribution of dates in the current sample, and reflects the approach taken in several other growth curve analyses to modeling a combination of aging and cohort effects (Raudenbush and Chan 1993). Because the number of participants born before 1910 or after 1935 was very small, these individuals were grouped with first and last cohorts, respectively, resulting in the following set of birth cohorts: 1900-1914, 1915-1919, 1920-1924, 1925-1929, 1930-1936. 


\section{Missing Data Imputation}

Listwise deletion of cases with data missing due to item nonresponse would have resulted in a loss of 19.7 percent of otherwise valid observations. To address this issue, multiple imputation of missing values using the Markov Chain Monte Carlo (MCMC) method was conducted with the SAS (SAS Institute, Cary, NC) 9.2 PROC MI function, based on a model that included all key study variables at each wave. The MCMC method uses the observed joint distributions of nonmissing model variables to simulate a series of randomly drawn values to replace each missing value (Horton and Lipsitz 2001). Consistent with recommendations based on multiple imputation theory (Graham, Olchowski, and Gilreath 2007), five sets of imputed values were independently drawn, and all analyses were conducted separately on each of the resulting data sets. After imputation, there were 2,932 observations from 1,122 individual respondents, which form the basis for all analyses presented.

\section{Model Specification}

Growth curve analysis was conducted based on a hierarchical linear modeling approach (West, Welch, and Galecki 2007), in which each individual participant is treated as a cluster within which successive longitudinal observations are nested. Using this method, a growth curve model expressing average age-related change within individuals is derived based on weighted composites of the trajectories of all participants, including those who left the study prior to Wave 4. This method also allows for a general model to be estimated across the range of ages represented in the sample, even though each participant was followed only up to a span of seven years. Analyses were conducted using the SAS 9.2 MIXED procedure, applying a variance components covariance matrix, with random intercept and age effects at the participant level. Preliminary analyses revealed no evidence of a significant quadratic age effect for any of these dependent variables; full analyses thus examine only linear change.

Fixed effects were added to the model in two stages. First, an unconditional growth model, including an age effect only, was constructed. This type of model describes mean within-person change in the dependent variable, and can be expressed with the following formula:

$$
\text { prayer }_{i j}=\beta_{0}+\beta_{1} \text { Age }_{i j}+u_{0 i}+u_{1 i} A g e_{i j}+\varepsilon_{i j} .
$$

In this formula, prayer $_{i j}$ represents the mean predicted score on the dependent variable for individual $i$ at age $j ; \beta_{0}$ is the intercept for age, centered on the grand mean of all age values across all waves of 77.02 years; $\beta_{1}$ is the mean rate of linear age-related change in the dependent variable; $u_{0 i}$ is the random intercept, representing intraindividual variation in mean of the dependent variable across ages; $u_{1 i}$ is the random effect for age, representing individual difference in the slope of age-related change in the dependent variable; and $\varepsilon_{i j}$ is the random error term for individual $i$ at age $j$.

The full model adds a range of explanatory variables including cohort, race, gender, education, religious service attendance, and spiritual support from the congregation. For each of these explanatory factors (with the exception of cohort), two terms were fitted: a main effect, representing the relationship of the variable with the mean level of the dependent variable, and an interaction with age, indicating its relationship with the trajectory of change in the dependent variable over time. Thus, the full model can be represented with the following 
formula:

$$
\begin{aligned}
\text { prayer }_{i j}= & \beta_{0}+\beta_{1} \text { Age }_{i j}+\beta_{2} \text { Cohort }_{i}+\beta_{3} \text { Cohort }_{i}+\beta_{4} \text { Cohort }_{i}+\beta_{5} \text { Cohort }_{i} \\
& +\beta_{6} \text { Race }_{i}+\left(\beta_{7} \text { Race }_{i} \times \text { Age }_{i j}\right)+\beta_{8} \text { Gender }_{i}+\left(\beta_{9} \text { Gender }_{i} \times \text { Age }_{i j}\right) \\
& +\beta_{10} \text { Education }_{i}+\left(\beta_{11} \text { Education }_{i} \times \text { Age }_{i j}\right)+\beta_{12} \text { Attendance }_{i j} \\
& +\left(\beta_{13} \text { Attendance }_{i j} \times \text { Age }_{i j}\right)+\beta_{14} \text { Support }_{i j}+\left(\beta_{15} \text { Support }_{i j} \times \text { Age }_{i j}\right) \\
& +u_{0 i}+u_{1 i} \text { Age }_{i j}+\varepsilon_{i j} .
\end{aligned}
$$

In each case, the main effect indicates the relationship of the variable with congregational support at the grand mean of the sample (77.02 years), and the multiplicative effect with age indicates the change in units of the dependent variable per year of age associated with a unit increase in the corresponding variable. Note that race, gender, and education are treated as constant at all ages within individual, but attendance and support vary both between individuals and within individuals by age. Cohort, race, and gender are represented by dichotomous variables; education, attendance, and support are each centered on their grand means.

Finally, for the models involving prayer contents outcomes, prayer frequency was included as a time-varying covariate, to take into account the possible confounding effect of changing total prayer on changes in specific types of prayer. That is, if prayer of all types increases with age, any particular form of prayer may appear to increase in absolute terms. Since the outcome of interest is change in each category relative to other forms of prayer, it is appropriate to include the control, thus:

$$
\begin{aligned}
\text { contents }_{i j}= & \beta_{0}+\beta_{1} \text { Age }_{i j}+\beta_{2} \text { Cohort }_{i}+\beta_{3} \text { Cohort }_{i}+\beta_{4} \text { Cohort }_{i}+\beta_{5} \text { Cohort }_{i} \\
& +\beta_{6} \text { Race }_{i}+\left(\beta_{7} \text { Race }_{i} \times \text { Age }_{i j}\right)+\beta_{8} \text { Gender }_{i}+\left(\beta_{9} \text { Gender }_{i} \times \text { Age }_{i j}\right) \\
& +\beta_{10} \text { Education }_{i}+\left(\beta_{11} \text { Education }_{i} \times \text { Age }_{i j}\right)+\beta_{12} \text { Attendance }_{i j} \\
& +\left(\beta_{13} \text { Attendance }_{i j} \times \text { Age }_{i j}\right)+\beta_{14} \text { Support }_{i j}+\left(\beta_{15} \text { Support }_{i j} \times \text { Age }_{i j}\right) \\
& +\beta_{16} \text { PrayerFrequency }_{i j}+\left(\beta_{17} \text { PrayerFrequency }_{i j} \times \text { Age }_{i j}\right) \\
& +u_{0 i}+u_{1 i} \text { Age }_{i j}+\varepsilon_{i j} .
\end{aligned}
$$

\section{RESUltS}

Descriptive statistics for data used in estimating the growth curve models are presented in Table 2. Unconditional and full growth curve models for prayer frequency are summarized in Table 3. Although no significant within-person change was detected in the unconditional model $(b=.005,95$ percent confidence interval, CI, [-.003, .01], $p=.23)$, a positive age slope emerged after other model factors were controlled $(b=.02,95$ percent CI $[.005, .04], p=.01)$, consistent with H1. More frequent prayer was found among African Americans $(b=-.49,95$ percent CI $[-.61,-.37], p<.001)$, women $(b=.49,95$ percent CI $[.38, .61], p<.001)$, and was associated with more frequent attendance at religious services $(b=.16,95$ percent CI $[.13, .19]$, $p<.001)$, and with receiving greater levels of spiritual support $(b=.03,95$ percent CI [.02, .04], $p<.001)$. However, no model variables showed any interaction with age, indicating that they had no relationship with the rate of change in prayer frequency. Random effects variance indicated that there was significant variability between individuals both in the mean frequency of prayer at the intercept $(b=.57,95$ percent CI $[.47, .66], p<.001)$, and in the age slope representing change in prayer frequency $(b=0.002,95$ percent CI [0.0005, .003], $p=.007)$.

Model summaries for prayer beliefs are presented in Table 4, and reveal results generally consistent with $\mathrm{H} 2$. The unconditional model indicated that the belief that one's prayers are answered tended to decline with age ( $b=-.007,95$ percent CI $[-.02,-.002], p=.01)$. The full model revealed that this slope was related to education $(b=-.002,95$ percent CI $[-.003$, 
Table 2: Descriptive statistics

\begin{tabular}{|c|c|c|c|c|c|}
\hline & Wave 1 & Wave 2 & Wave 3 & Wave 4 & $\begin{array}{c}\text { All } \\
\text { Observations }\end{array}$ \\
\hline & $(N=1,122)$ & $(N=681)$ & $(N=634)$ & $(N=496)$ & $(N=2,932)$ \\
\hline Age & $74.72(6.34)$ & $76.96(5.85)$ & $78.64(5.53)$ & $80.21(5.19)$ & $77.02(6.22)$ \\
\hline Race (white) & $521(46.4 \%)$ & $313(46.0 \%)$ & $317(50.0 \%)$ & $241(48.6 \%)$ & $1,392(47.5 \%)$ \\
\hline Gender (female) & $725(64.6 \%)$ & $443(65.0 \%)$ & $411(64.8 \%)$ & $329(66.3 \%)$ & $1,908(65.1 \%)$ \\
\hline Education & $11.39(3.48)$ & $11.68(3.36)$ & $11.83(3.24)$ & $11.94(3.32)$ & $11.64(3.38)$ \\
\hline Attendance & $7.07(1.57)$ & $7.32(1.05)$ & $7.37(1.37)$ & $7.46(1.33)$ & $7.26(1.46)$ \\
\hline Spiritual support & $11.91(4.45)$ & $11.68(4.37)$ & 11.79 (4.68) & $11.48(4.76)$ & $11.76(4.54)$ \\
\hline Prayer frequency & $7.18(1.34)$ & $7.28(1.18)$ & $7.33(1.09)$ & $7.43(1.19)$ & $7.26(1.23)$ \\
\hline \multicolumn{6}{|l|}{ Prayer beliefs } \\
\hline $\begin{array}{l}\text { My prayers are } \\
\text { answered }\end{array}$ & $2.99(.81)$ & $3.03(.76)$ & $2.93(.78)$ & $3.01(.79)$ & $2.99(.79)$ \\
\hline Learning to wait & $3.28(.58)$ & $3.40(.59)$ & $3.51(.60)$ & $3.50(.62)$ & $3.40(.60)$ \\
\hline Only God knows & $3.39(.58)$ & $3.45(.58)$ & $3.55(.56)$ & $3.57(.56)$ & $3.47(.58)$ \\
\hline \multicolumn{6}{|l|}{ Prayer contents } \\
\hline Pray for others & $6.73(1.68)$ & $7.03(1.37)$ & $7.11(1.31)$ & $7.10(1.34)$ & $6.94(1.49)$ \\
\hline Pray for God's will & $3.44(.79)$ & $3.51(.73)$ & $3.63(.68)$ & $3.65(.68)$ & $3.53(.74)$ \\
\hline Pray in thanksgiving & $3.47(.74)$ & $3.65(.63)$ & $3.72(.55)$ & $3.76(.56)$ & $3.62(.66)$ \\
\hline Pray for own health & $3.44(.79)$ & $3.58(.69)$ & $3.56(.73)$ & $3.66(.67)$ & $3.53(.74)$ \\
\hline $\begin{array}{l}\text { Pray for material } \\
\text { things }\end{array}$ & $1.69(.90)$ & $1.78(.97)$ & $1.66(.95)$ & $1.90(1.03)$ & $1.74(.95)$ \\
\hline
\end{tabular}

Note: Values represent means and (standard deviations), except for race and gender, which represent group $n$ and (percentage).

$-.00007], p=.04)$, with these declines evident only among those with higher than average levels of education. Learning to wait showed no age-related change in the unconditional model $(b=.004$, 95 percent CI [-.0005, .008], $p=.09$ ), but showed within-person increase once other factors were included $(b=.03,95$ percent CI $[.02, .04], p<.001)$. The belief that only God knows what is best showed an upward trajectory in the unconditional model $(b=.004,95$ percent CI [.006, .008], $p=.02)$, which was significantly stronger in the full model $(b=.02$, 95 percent CI [.01, .03], $p<.001)$. For both of the latter two outcomes, cohort effects appeared to wholly or partially mask the unconditional growth curve, as individuals born earlier endorsed these trust-based expectancies somewhat less strongly to begin with. For all three outcomes, both frequency of religious attendance and spiritual support from the congregation were related to stronger endorsement across ages. Random effects indicated significant variability between individuals in intercepts of beliefs, but not in age slopes.

Model summaries for prayer contents are presented in Table 5. Amount of prayer for others showed within-person increase with age. Partially consistent with $\mathrm{H} 3$, patterns of within-person increase with age were observed in the unconditional models for prayer for others $(b=.02,95$ percent CI [.005, .03], $p=.006)$, for God's will $(b=.007,95$ percent CI [.002, .01], $p=.006)$, in thanksgiving $(b=.01,95$ percent CI [.006, .02], $p<.001)$, and for health $(b=.01,95$ percent CI $[.005, .02], p<.001)$. In the full models, significant growth emerged for all prayer contents variables: for others $(b=.04,95$ percent CI $[.02, .06], p<.001)$, for God's will $(b=.02,95$ percent CI [.01, .03], $p<.001)$, in thanksgiving $(b=.03,95$ percent CI $[.02, .04], p<.001)$, for guidance $(b=.02,95$ percent CI $[.01, .03], p<.001)$, for health $(b=.02,95$ percent CI $[.002, .03], p=.02)$, and for material things $(b=.02,95$ percent CI $[.008, .04], p=.002)$. More frequent worship attendance was related to greater prayer for others $(b=.06,95$ percent CI $[.03$, 
Table 3: Prayer frequency growth curve models

\begin{tabular}{|c|c|c|c|c|}
\hline & \multicolumn{2}{|c|}{ Unconditional Model } & \multicolumn{2}{|c|}{ Full Model } \\
\hline & $b$ & $95 \%$ CI & $b$ & $95 \% \mathrm{CI}$ \\
\hline Intercept & $7.20^{* * * *}$ & {$[7.14,7.27]$} & $6.95^{* * *}$ & {$[6.79,7.11]$} \\
\hline Age slope & .005 & {$[-.003, .01]$} & $.02^{*}$ & {$[.005, .04]$} \\
\hline Cohort 1 & & & $-.36^{*}$ & {$[-.70,-.02]$} \\
\hline Cohort 2 & & & -.003 & {$[-.26, .26]$} \\
\hline Cohort 3 & & & -.10 & {$[-.29, .09]$} \\
\hline Cohort 4 & & & -.06 & {$[-.21, .09]$} \\
\hline White & & & $-.49^{* * *}$ & {$[-.61,-.37]$} \\
\hline$\times$ Age slope & & & -.005 & {$[-.02, .01]$} \\
\hline Female & & & $.49^{* * *}$ & {$[.38, .61]$} \\
\hline$\times$ Age slope & & & -.002 & {$[-.02, .01]$} \\
\hline Education & & & -.01 & {$[-.03, .007]$} \\
\hline$\times$ Age slope & & & -.011 & {$[-.003, .002]$} \\
\hline Attendance & & & $.16^{* * *}$ & {$[.13, .19]$} \\
\hline$\times$ Age slope & & & -.004 & {$[-.009, .0006]$} \\
\hline Spiritual support & & & $.03^{* * *}$ & {$[.02, .04]$} \\
\hline$\times$ Age slope & & & .0004 & {$[-.001, .002]$} \\
\hline \multicolumn{5}{|c|}{ Random Effects Variance } \\
\hline Age & $.002^{*}$ & {$[.0003, .004]$} & $.002^{* *}$ & {$[.0005, .003]$} \\
\hline Intercept & $.90^{* * * *}$ & {$[.078,1.02]$} & $.57^{* * * *}$ & {$[.47, .66]$} \\
\hline Residual & $.65^{* * *}$ & {$[.60, .69]$} & $.66^{* * *}$ & {$[.61, .71]$} \\
\hline
\end{tabular}

${ }^{*} p<.05,{ }^{* *} p<.01,{ }^{* * *} p<.001$.

$.08], p<.001)$, for God's will $(b=.02,95$ percent CI [.007, .04], $p=.005)$, and in thanksgiving ( $b=.03,95$ percent CI [.01, .05], $p<.001)$, but not the other prayer contents. However, more spiritual support from the congregation was related to greater use of all of these prayer contents. The only case in which a religion variable had a significant impact on the slope for age-related change was with respect to prayer for material things, in which case more frequent worship attendance was related to a slower rate of growth over time $(b=-.005,95$ percent CI [-.009, $-.0006], p=.03$ ). In addition, race was significantly related to differences in the slope for prayer for one's own health, such that white older adults tended to increase their use of this type of prayer more rapidly with age $(b=.01,95$ percent CI $[.002, .02], p=.02)$. Random effects results showed that there was significant between-person variability in intercepts for all prayer contents variables, but between-person variability in slope emerged only for prayer for others $(b=.003$, 95 percent CI [.002, .004], $p<.001)$, for God's will $(b=.0004,95$ percent CI [.00007, .0008], $p=.02)$, and in thanksgiving $(b=.0005,95$ percent CI $[.0001, .0008], p<.001)$.

\section{Discussion}

The results of this study indicate that there may be patterns of change within the course of older adulthood not only in terms of how much people pray, but also in their beliefs about prayer, and in the contents of what they pray for. These results partially support the hypotheses set forth in this article. Consistent with H1, there was a mean pattern of increasing prayer frequency with age, although this became apparent only when certain other factors were controlled in the model. The strong positive relationship between private prayer frequency and public worship attendance may be partially responsible for masking this increase in the unconditional model, if 


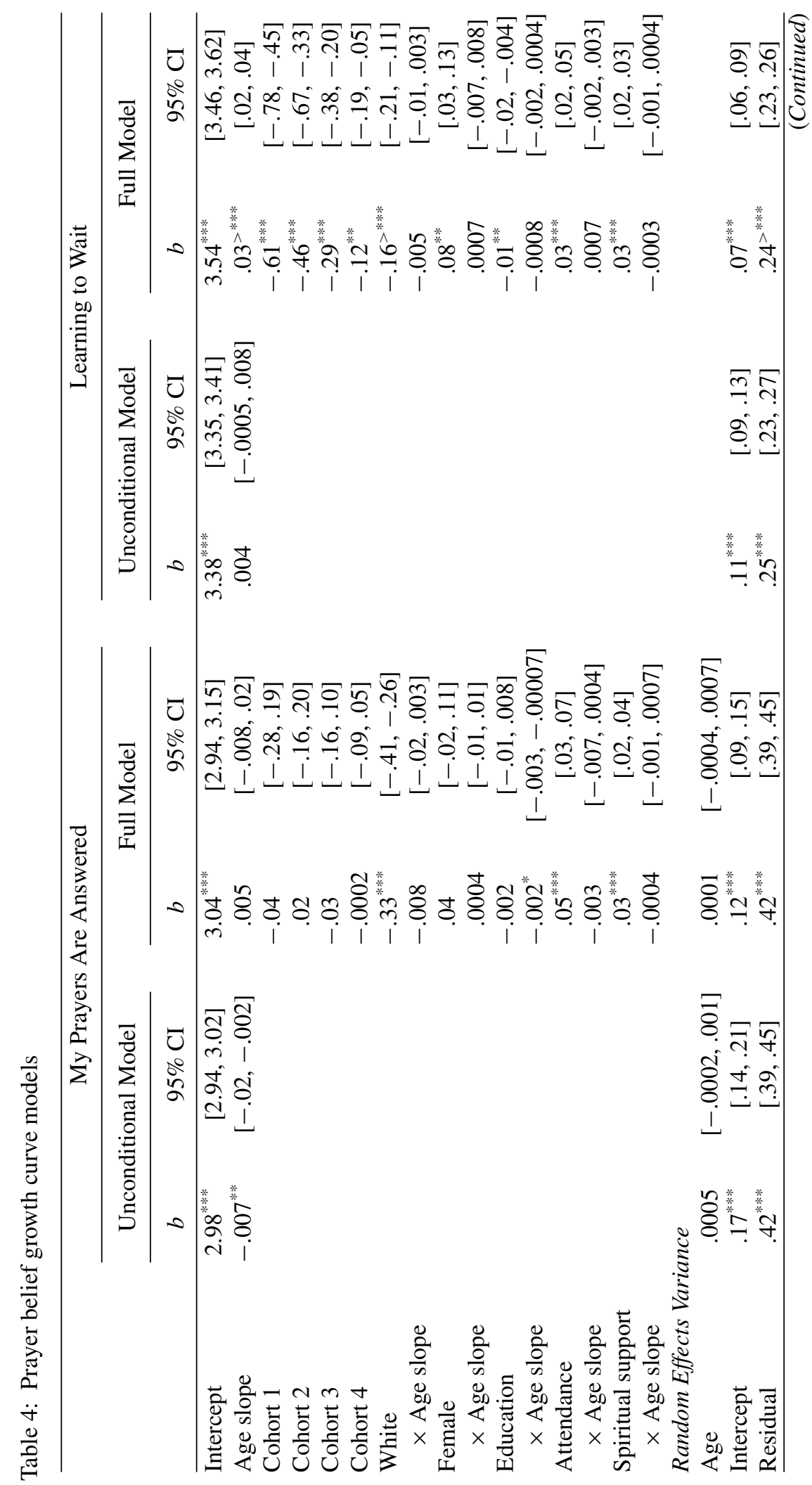




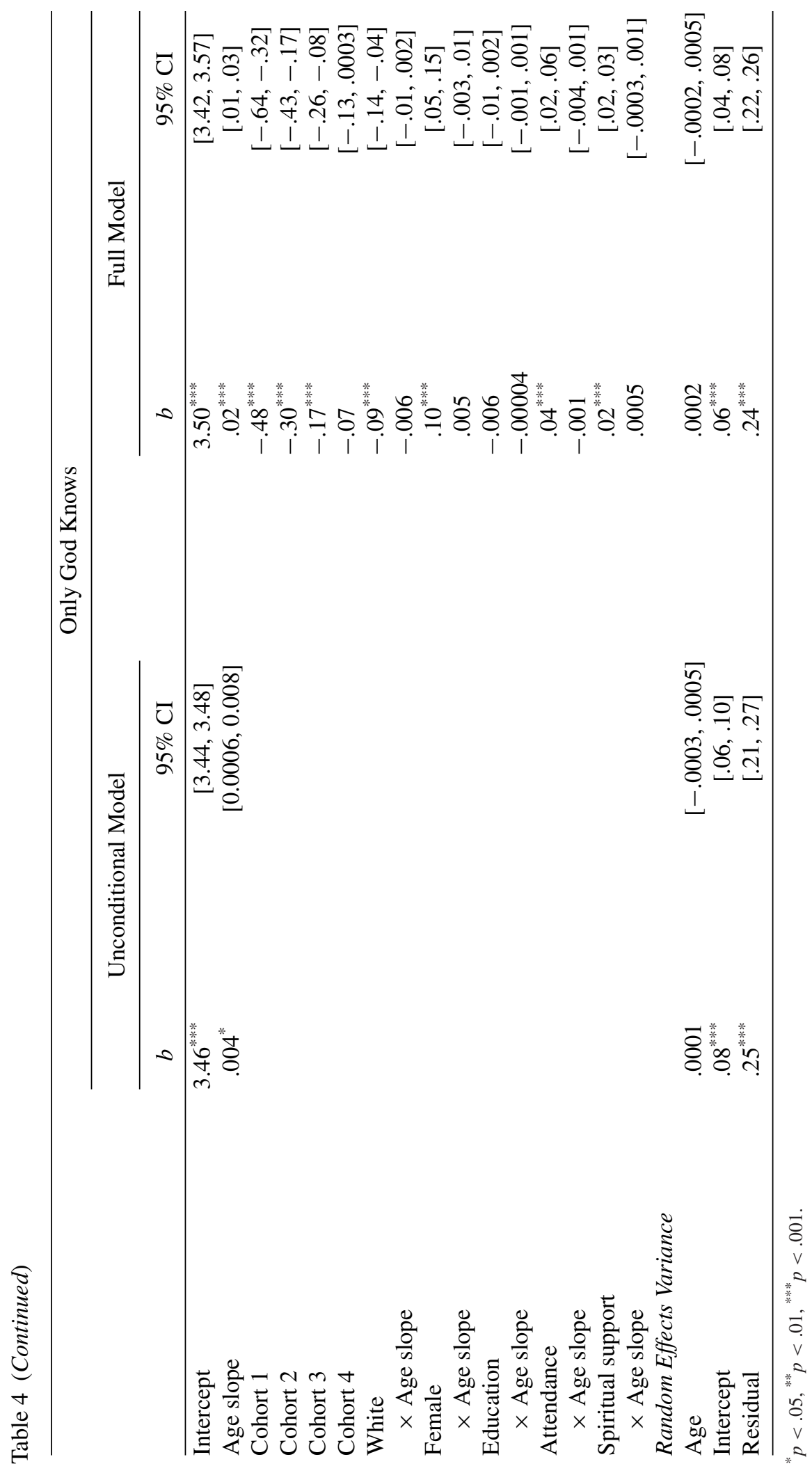




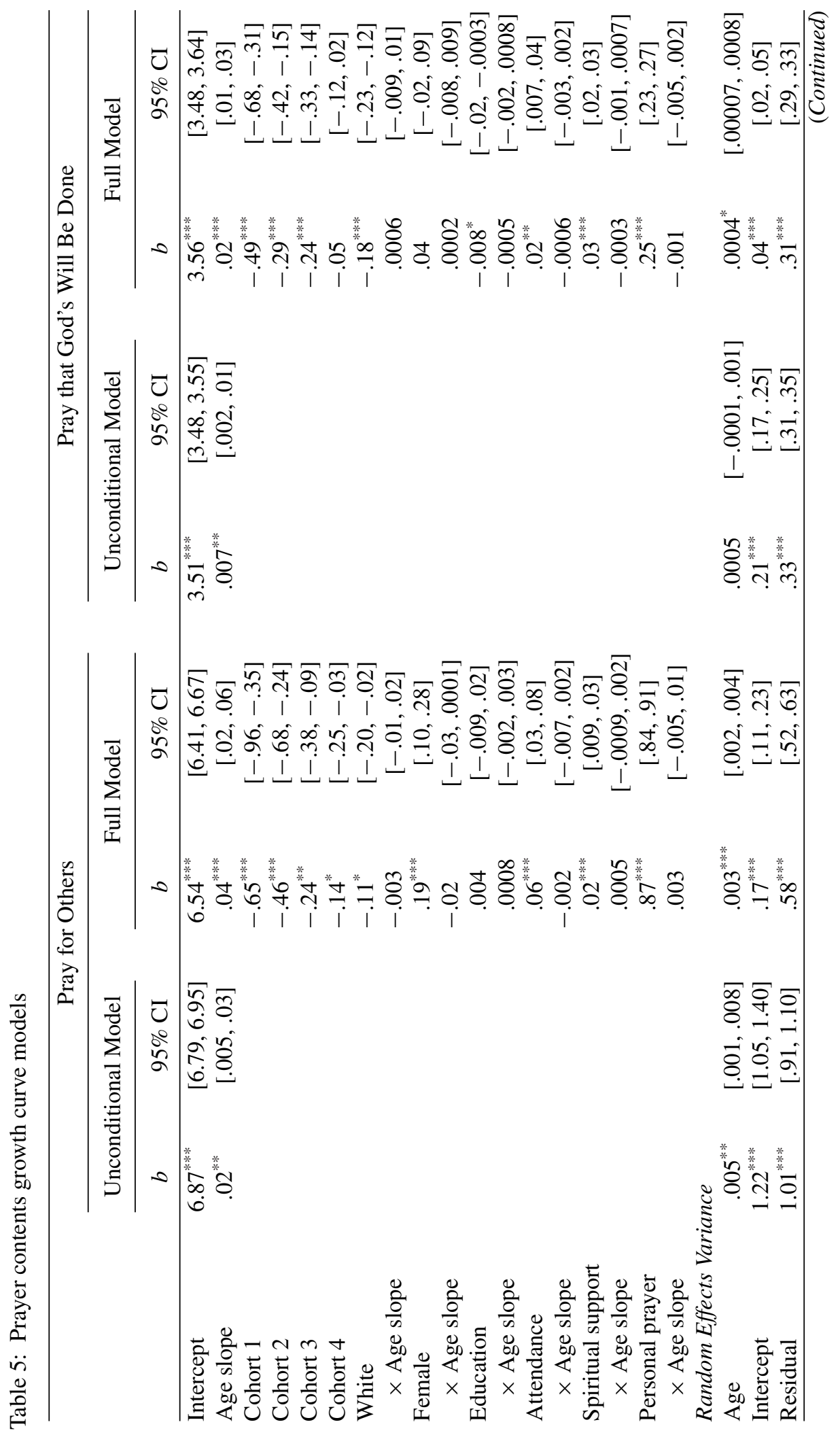




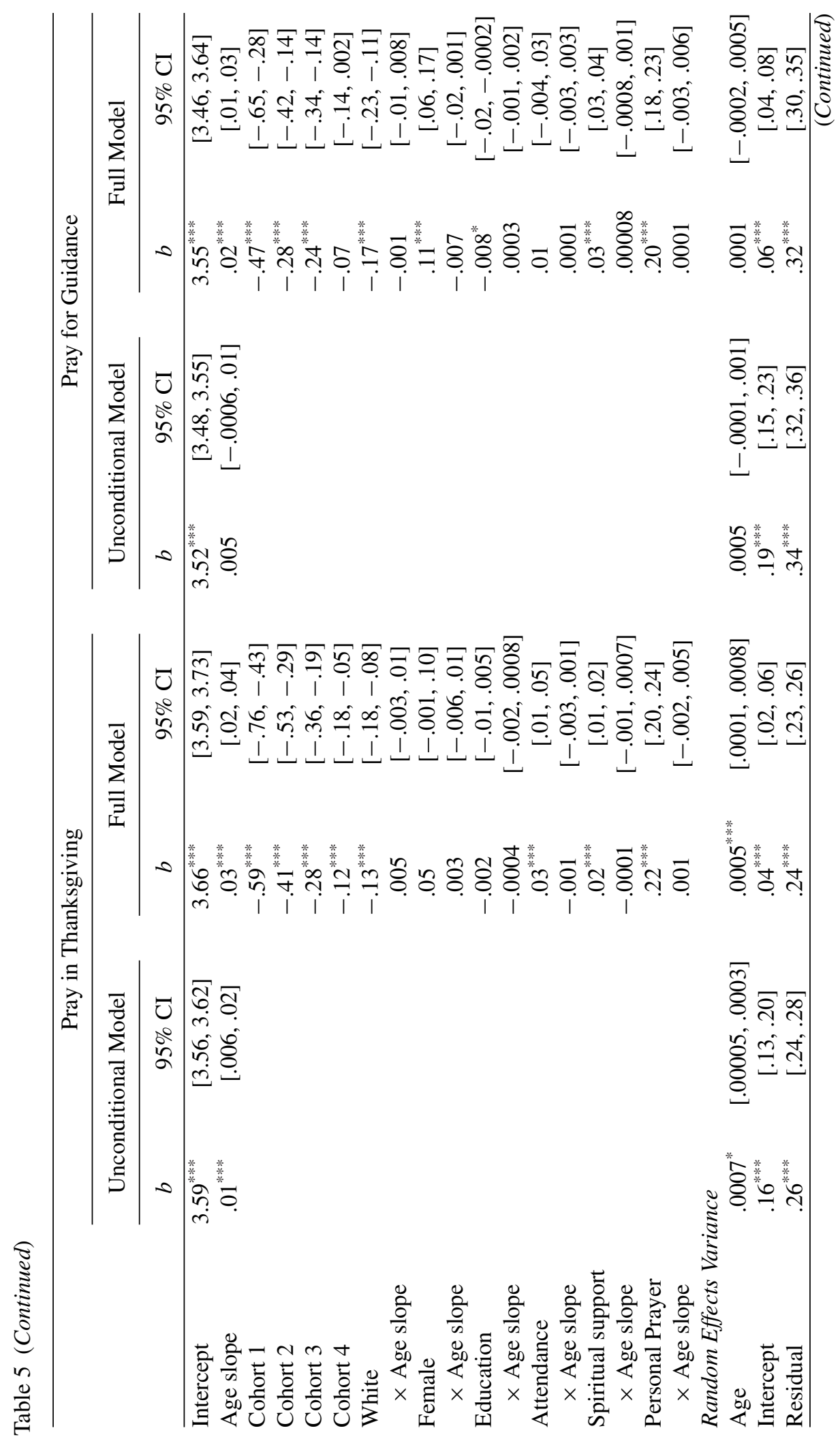




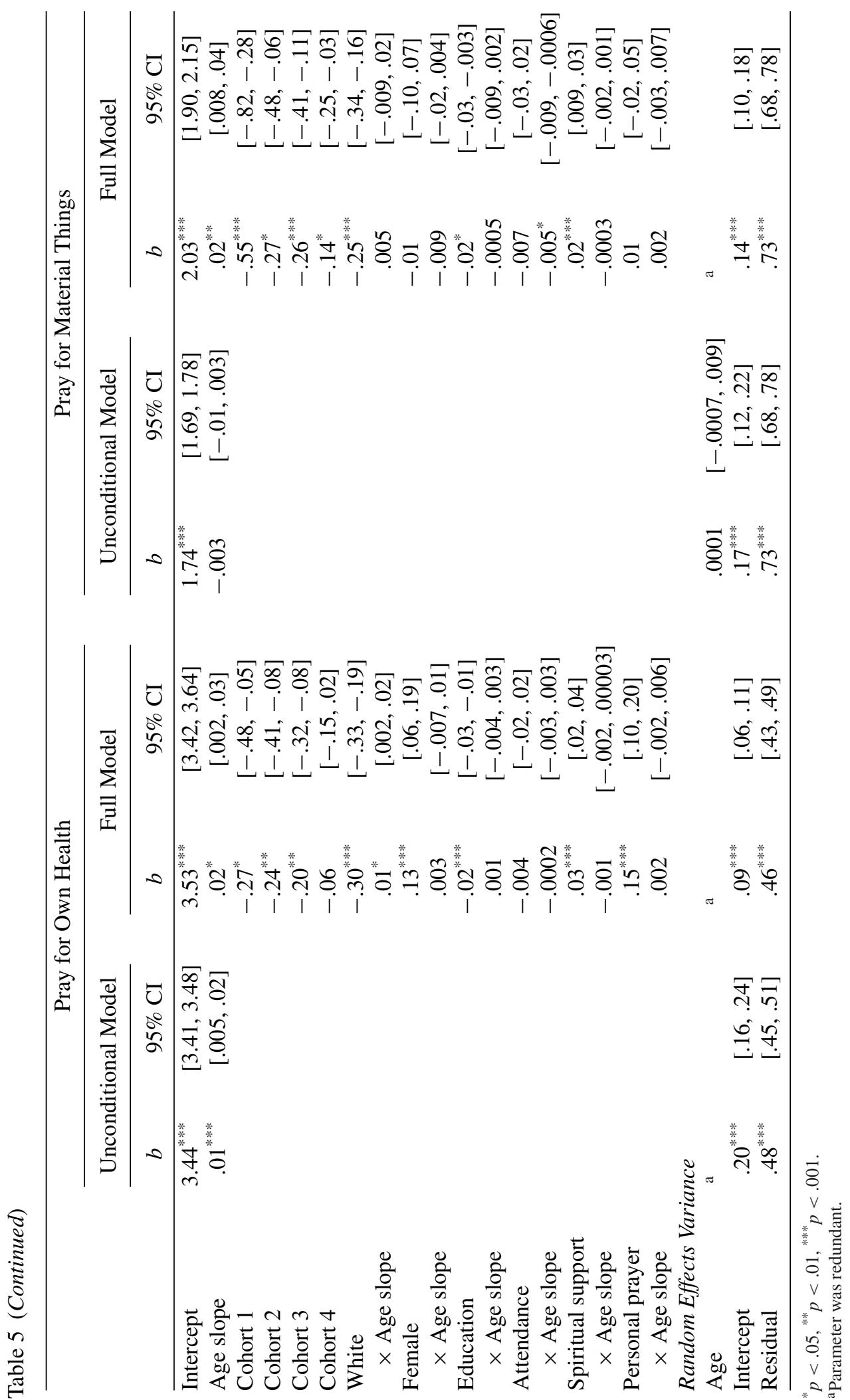


attendance declines at the oldest ages. $\mathrm{H} 2$, which predicted that more mature, trust-based, prayer expectancies would increase during late life, was also supported. Although older adults did not change in their propensity to think their prayers were answered, they did increasingly come to endorse the ideas that one must learn to wait for God's answers, and that God does not always respond to prayers in the expected way because only he knows what is best. H3, which predicted a shift toward more mature prayer contents, was only partially supported. In fact, prayer with contents of all varieties appeared to increase, even after controlling for the general increase in prayer charted in $\mathrm{H} 1$ above, including prayer for one's own health and for material goods. H4 was not supported. Although church involvement and spiritual support were strongly related to more frequent prayer of all types, and with more mature prayer beliefs, higher levels of involvement and support were not related to more rapid changes in these factors across the course of older adulthood.

The clearest implication of these results is that active change in prayer belief, as well as behavior, appears to continue during older adulthood. Though this supports previous findings based on cross-sectional comparisons by age cohort (Baker 2008; Levin and Taylor 1997), and helps mitigate against the possibility that those findings might be attributed to generational shifts alone, it also expands upon them by suggesting that these changes may be rooted in deeper trends than increasing religiousness alone. These findings may be explained by Schulz and Heckhausen's (1996) widely cited theory of life course development. They argue that as people grow older, and their resources dwindle, they gradually begin to relinquish primary control in some domains of life, preferring instead to rely on secondary control strategies. Viewed within the context of this theoretical framework, increasing reliance on prayer may be construed as a specific type of secondary control strategy. Late life is already a period of interest to many researchers concerned with religion, but this study highlights the importance of considering changes that may occur within old age itself. The emergence of cohort effects in several models further emphasize the point that care should be taken in treating older adults as a homogeneous group in this regard, and suggests that care must be taken in relating age differences to change as opposed to cohort differences.

Although the advance of more mature prayer expectancies and behavior was anticipated based on the premise of faith development (Fowler 1991; Streib 2001), the results of this study are ambiguous with respect to those predictions. In the case of trust-based expectancies, it appeared to hold true, as older adults endorsed these beliefs more with age. However, since alternative expectancies were not measured longitudinally, the possibility that alternative and less mature expectancies also increased over time cannot be assessed. This would appear to be paradoxical from a faith development perspective, but might be consistent with the results of this study regarding prayer contents. Specifically, it appeared that more mature prayer contents (e.g., prayer for others, prayer for God's will to be done) increased in parallel to less mature contents (e.g., prayer for material goods). Further research is needed to place these results in a broader context. Further examination of prayer for one's own health may be an especially important direction for future research. Although this study found that this type of prayer increased during the course of older adulthood, it remains to be seen whether this pattern corresponds directly with increasing health problems, and whether it has reciprocal associations with better health outcomes later. More generally, it remains an open question to what extent these changes are linked with specific stressful life events that may become increasingly likely during older adulthood-like health problems, financial strain, and the death of a spouse-as compared to reflecting internal maturational processes.

Limitations of the present study include the inherent difficulties in separating age, period, and cohort effects when examining change, even with the advantages provided by longitudinal data. For example, although the time between Waves 1 and 4 was relatively long, at seven years, it covers only a relatively small segment of the entire course of older adulthood. Thus, within-individual change was tracked only across a subset of the total range of ages covered 
by the entire model. As a result, change at the oldest ages is disproportionately estimated by members of the earliest cohorts, and vice versa. The presence of age-by-cohort interactions (i.e., the possibility that different patterns of age-related change occurred for members of different birth cohorts) thus cannot be fully evaluated. Collection of further data across a longer period, and with more frequent observations, would help to address this limitation, as well as allowing for better evaluation of the possibility of curvilinear change over time. In addition, as mentioned earlier, trust-based expectancies were measured with positively worded survey items only. Direct measurement of alternative expectancies would provide a better evaluation of the faith maturation hypothesis. Finally, the extent to which previous responses to repeated prayer items may have influenced responses in later waves, for example, to maintain a consistent self-image or to present a pattern of improvement over time, remains unknown.

George Allen Coe was one of the founders of the psychology of religion. Writing in 1902, he argued that: "Prayer is the heart of religion. When you have told what a man's prayers are like, you have told what his religion is" (Coe 1902:329). Since that time, great strides have been made in empirical studies of prayer. But most of this research has been very static in nature, focusing primarily on data that have been gathered at a single point in time. As a result, the dynamic life of prayer has been largely overlooked. When viewed at the broadest level, we hope the findings we have provided encourage other investigators to help address this imbalance in the literature by exploring how this core facet of religious life changes over time.

\section{ReFERENCES}

Ai, Amy L., E. Mitchell Seymour, Terrence N. Tice, Ziad Kronfol, and Steven F. Bolling. 2009. Spiritual struggle related to plasma interleukin-6 prior to cardiac surgery. Psychology of Religion and Spirituality 1(2):112-28.

Ai, Amy L., Paul Wink, Terrence Tice, Steven Bolling, and Marshall Shearer. 2009. Prayer and reverence in naturalistic, aesthetic, and socio-moral contexts predicted fewer complications following coronary artery bypass. Journal of Behavioral Medicine 32(6):570-81.

Baker, Joseph O. 2008. An investigation of the sociological patterns of prayer frequency and content. Sociology of Religion 69(2):169-85.

Bamford, Christi and Kristin Hansen Lagattuta. 2010. A new look at children's understanding of mind and emotion: The case of prayer. Developmental Psychology 46(1):78-92.

Carstensen, Laura L., Derek M. Isaacowitz, and Susan T. Charles. 1999. Taking time seriously: A theory of socioemotional selectivity. American Psychologist 54(3):165-81.

Coe, George Albert. 1902. The religion of a mature mind. Chicago: Fleming H. Revell.

Erikson, Erik H. 1968. Identity, youth, and crisis. New York: W. W. Norton.

Exline, Julie J., Ann M. Yali, and Marci Lobel. 1999. When God disappoints: Difficulty forgiving God and its role in negative emotion. Journal of Health Psychology 4(3):365-79.

Fowler, James W. 1991. Stages in faith consciousness. New Directions for Child and Adolescent Development 52(1): 27-45.

Graham, John, Allison Olchowski, and Tamika Gilreath. 2007. How many imputations are really needed? Some practical clarifications of multiple imputation theory. Prevention Science 8(3):206-13.

Heiler, Friedrich. 1932. Prayer: A study in the history and psychology of religion. New York: Oxford University Press.

Hoare, Carol Hren. 2002. Erikson on development in adulthood: New insights from the unpublished papers. New York: Oxford University Press.

Horton, Nicholas J. and Stuart R. Lipsitz. 2001. Multiple imputation in practice. American Statistician 55(3):244-54.

James, William. 1902. The varieties of religious experience: A study in human nature. New York: Modern Library.

Kelley-Moore, Jessica A. and Kenneth F. Ferraro. 2001. Functional limitations and religious service attendance in later life. Journals of Gerontology Series B: Psychological Sciences and Social Sciences 56(6):S365-73.

Krause, Neal. 2002. Church-based social support and health in old age. Journals of Gerontology Series B: Psychological Sciences and Social Sciences 57(6):S332-47.

. 2004. Assessing the relationships among prayer expectancies, race, and self-esteem in late life. Journal for the Scientific Study of Religion 43(3):395-408.

. 2008. Aging in the church: How social relationships affect health. West Conshohocken, PA: Templeton Foundation Press.

. 2011. The perceived prayers of others, stress, and change in depressive symptoms over time. Review of Religious Research 53(3):341-56. 
Krause, Neal and Linda M. Chatters. 2005. Exploring race differences in a multidimensional battery of prayer measures among older adults. Sociology of Religion 66(1):23-43.

Krause, Neal, Tina Meltzer, and David L. Morgan. 2000. Using focus groups to explore the nature of prayer in late life. Journal of Aging Studies 14(2):191-212.

Ladd, Kevin L. and Bernard Spilka. 2002. Inward, outward, and upward: Cognitive aspects of prayer. Journal for the Scientific Study of Religion 41(3):475-84.

Levin, Jeffrey S. and Robert Joseph Taylor. 1997. Age differences in patterns and correlates of the frequency of prayer. Gerontologist 37(1):75-89.

Masters, Kevin and Glen Spielmans. 2007. Prayer and health: Review, meta-analysis, and research agenda. Journal of Behavioral Medicine 30(4):329-38.

McCaffrey, Anne M., David M. Eisenberg, Anna T. R. Legedza, Roger B. Davis, and Russell S. Phillips. 2004. Prayer for health concerns: Results of a national survey on prevalence and patterns of use. Archives of Internal Medicine 164(8):858-62.

Pew Forum on Religion and Public Life. 2008. U.S. religious landscape survey. Available at http://religions.pewforum.org/, accessed July 18, 2011.

Poloma, Margaret M. 1991. The effects of prayer and prayer experiences on measures of general well-being. Journal of Psychology and Theology 19(1):71-83.

Poloma, Margaret M. and Brian F. Pendleton. 1989. Exploring types of prayer and quality of life: A research note. Review of Religious Research 31(1):46-53.

Raudenbush, Stephen W. and Wing-Shing Chan. 1993. Application of a hierarchical linear model to the study of adolescent deviance in an overlapping cohort design. Journal of Consulting and Clinical Psychology 61(6):941-51.

Schulz, Richard and Jutta Heckhausen. 1996. A life span model of successful aging. American Psychologist 51(7):702-14.

Sosis, Richard. 2004. The adaptive value of religious ritual: Rituals promote group cohesion by requiring members to engage in behavior that is too costly to fake. American Scientist 92(2):166-72.

Streib, Heinz. 2001. Faith development theory revisited: The religious styles perspective. International Journal for the Psychology of Religion 11(3):143-58.

United Nations. 2010. World population ageing 2009. New York: United Nations Department of Economic and Social Affairs, Population Division.

United States Bureau of Census. 2008. Projections of the population by selected age groups and sex for the United States: 2010 to 2050.

West, Brady T., Kathleen B. Welch, and Andrzej T. Galecki. 2007. Linear mixed models: A practical guide using statistical software. Boca Raton, FL: Chapman and Hall/CRC.

Whittington, Brandon L. and Steven J. Scher. 2009. Prayer and subjective well-being: An examination of six different types of prayer. International Journal for the Psychology of Religion 20(1):59-68. 